\title{
FAQs
}

\section{Dengue-Fieber - das sollten Sie wissen!}

\section{Wann besteht Dengue-Verdacht?}

Typische Symptome sind plötzlich eintretendes hohes Fieber, schwere Kopfschmerzen, evtl. retroorbitale Schmerzen, starke Muskel- und Knochenschmerzen (,Knochenbrecher-Fieber"), evtl. nur diskretes morbilliformes Exanthem, in schweren Fällen Hämorrhagien.

Wie unterscheidet sich das DengueFieber von der „normalen“ Virusgrippe?

Bei Influenza treten vor allem respiratorische Symptome auf, die bei Dengue fehlen. Dagegen sind Allgemeinsymptome wie Kopf-, Muskel- und Gliederschmerzen, Fieber und Schüttelforst bei Influenza in der Regel weniger stark ausgeprägt. In der Praxis kann diese Differenzierung u.U. schwierig sein.

Wie soll man im Verdachtsfall vorgehen? Bei Nachweis von Dengue-Virus besteht Labormeldepflicht; diagnostisch ausschlaggebend ist der lgM-Nachweis sowie der Aufenthalt in einer Endemieregion. Therapie: symptomatisch, in erster Linie Fiebersenkung, evtl. Rehydratation. Antikoagulanzien und Thrombozytenhemmer (Aspirin) sind wegen der Blutungsgefahr kontraindiziert! Bei schweren Verläufen ist der Patient zu hospitalisieren (ggf. Kontaktaufnahme mit tropenmedizinisch erfahrenem Kollegen).

Prof. Dr. med. ANDREAS Sing a die Tigermücke braucht es beispielsweise Temperaturen von mindestens $27^{\circ} \mathrm{Cüber}$ zehn Tage.

MMW: Was soll man Urlaubern raten, die für dieses Jahr Madeira gebucht haben?

Fingerle: Sie müssen sich in jedem Fall vor Mückenstichen schützen. Also Mückenschutz verwenden, sich mit entsprechenden Repellentien einschmieren, auf langärmelige Kleidung achten. Aedes aegypti ist ja tagaktiv, man muss sich also den ganzen Tag über schützen. Der Ausbruch betrifft zwar vor allem den Süden der Insel, aber letztlich sollte man ganz Madeira als Risikogebiet ansehen. Die dortigen Gesundheitsbehörden warnen auf Plakaten vor kleineren, länger stehenden Wasseransammlungen: Pfützen, Blumentöpfe und Gießkannen, vor allem auf Friedhöfen oder in Vorgärten, aber auch offene Mülltonnen oder wassergefüllte Altreifen. Das sind phantastische Brutstätten für Mücken!

Interview: Dr. Elke Oberhofer 